\title{
SCREENING OF ORGANOGELATORS FOR STRUCTURING PALM SUPEROLEIN
}

\author{
SAW, M H*; LIM, W H*; YEOH, C B*; BADLISHAH SHAM BAHARIN ${ }^{\star *}$ and TAN, C P**
}

\begin{abstract}
The study was conducted to investigate the potential of several organogelators in structuring palm superolein such as polyglycerol behenic acid ester (PBAE), sunflower wax (SFW), fully hydrogenated palm-based monoacylglycerols, hard stearin and fully hydrogenated palm stearin. A simple inverted vial approach was used to observe the stability of the oleogels for 90 days at $15^{\circ} \mathrm{C}, 20^{\circ} \mathrm{C}$ and $25^{\circ} \mathrm{C}$. The results indicated that at least $8 \%(w / w)$ of fully hydrogenated palm-based monoacylglycerols was needed to form stable oleogels at all storage temperatures. For the hard stearin and fully hydrogenated palm stearin, 10\% (w/w) was still insufficient to structure the superolein at $20^{\circ} \mathrm{C}$ and $25^{\circ} \mathrm{C}$. In contrast, only $1 \%(w / w)$ of PBAE and SFW gelators were needed to form stable gels that lasted for 90 days at $15^{\circ} \mathrm{C}$ and $20^{\circ} \mathrm{C}$. The effectiveness of these gelators in structuring the superolein mainly relied on their solubility in the oil. The hard palm stearin and fully hydrogenated palm stearin were very much less effective to form superolein gel as compared to PBAE and SFW gelators due to their relatively higher solubility in the superolein. Therefore, these gelators were withdrawn from further investigation.
\end{abstract}

Keywords: superolein oleogel, polyglycerol behenic acid ester, sunflower wax.

Date received: 6 March 2019; Sent for revision: 7 March 2019; Accepted: 19 April 2019.

\section{INTRODUCTION}

Physical properties of oils and fats are mainly dependent on the chemical structure and polymorphic behaviour of the triacylglycerol (TAG) and the constituent fatty acids attached to the glycerol backbone (Birker and Padley, 1987). For many edible purposes, it is desirable to produce solid fats. Traditionally, fat products are structured by high melting TAG such as those high in trans fatty acids and saturated fat, which have demonstrated possible negative impact on human cardiovascular health (Zetzl and Marangoni, 2011; Tavernier et al., 2017). Recently, the USA Food

\footnotetext{
Malaysian Palm Oil Board, 6 Persiaran Institusi, Bandar Baru Bangi, 43000 Kajang,

Selangor, Malaysia.

E-mail: meihuey@mpob.gov.my

** Department of Food Technology, Faculty of Food Science and Technology, Universiti Putra Malaysia,

43400 UPM Serdang, Selangor, Malaysia.
}

and Drug Administration (FDA) is considering to propose a total removal of partial hydrogenated oils (trans fat) from human food due to the same reason (Kushairi et al., 2018). Organogelation has become a possible alternative to replace these conventional fats (Marangoni and Garti, 2011). The purpose of organogelation is to produce low saturation solid fat products using lower amounts of saturated components and higher amounts of liquid oil components. It involves soft matter systems with liquid oil as the continuous phase, entrapped in a three-dimensional network structure formed by self-assembled gelator molecules. Most of the research on oleogel preparations involves the use of soft vegetable oils such as sunflower oil, soyabean oil, safflower oil, olive oil, canola oil and rice bran oil (Toro-Vazquez et al., 2007; Ogutcu and Yilmaz, 2014; Doan et al., 2015; Jang et al., 2015).

There are many literatures that have discussed the use of palm oil fractions like palm stearin and palm mid fraction as structurants through 
conventional routes as crystalline fats (Nor Aini and Miskandar, 2007; Miskandar and Nor Aini, 2010; Jin et al., 2018). However, very limited literatures have discussed the use of the low saturation palm fractions such as palm olein, superolein or top olein for structuring of fats (Miskandar et al., 2004; Nur Haqim et al., 2018). Baran et al. (2014) and Pradhan et al. (2014) have reported the characteristics of organogels produced using palm oil that were used as matrices for the delivery of metronidazole in a controlled release manner. These palm oil-based oleogels are mainly for pharmaceutical purposes and not related to food applications.

In this study, few organogelators were selected including polyglycerol behenic acid ester (PBAE), sunflower wax (SFW), fully hydrogenated palmbased monoacylglycerols, hard stearin and fully hydrogenated palm stearin. Out of these gelators, SFW was found to be the most popular gelator which had shown great potential in gelling various vegetable oils (Hwang et al., 2011; 2012; 2015; Patel et al., 2015; Blake and Marangoni, 2015). There are also numerous studies that have investigated the use of monoacylglycerol as the gelling material, either in oil or oil in water systems (Da Pieve et al., 2010; Bin Sintang et al., 2017). As for the other materials, their usage as gelling agents has still not been wellstudied. Therefore, the objective of this study is to investigate their capability to form oleogel with palm superolein via a simple inverted vial test.

\section{MATERIALS AND METHODS}

\section{Materials}

Refined, bleached and deodourised superolein of iodine value (IV) 64 and soyabean oil (SBO) were obtained from PGEO Sdn Bhd (Johor, Malayisa). PBAE was obtained from Sakamoto Yakuhin Kogyo Co., Ltd (Osaka, Japan), food grade SFW with melting point of $77^{\circ} \mathrm{C}$ was obtained from Shri Balaji Driers (Karnataka, India), fully hydrogenated palm-based monoacylglycerol with high palmitic (MGHP), fully hydrogenated palm-based monoacylglycerol with high stearic (MGHO), fully hydrogenated palm stearin with IV 2 (PSIV2) and hard stearin with IV 14 (PSIV14) were obtained from Ecolex Sdn Bhd (Selangor, Malaysia).

\section{Acylglycerol Composition of Raw Materials}

Acylglycerol composition analysis of the palm superolein were performed using ultra-high performance liquid chromatography (U-HPLC) (ACQUITY UPLC H-Class System, Waters Cop., Milford, Massachusetts, USA) according to the AOCS Official Methods Ce 5c-89 (reapproved 2017) and Ce 5c-93 (reapproved 2017). The instrument was equipped with refractive index detector (Waters Cop., Milford, Massachusetts, USA) set at $35^{\circ} \mathrm{C}$, and a ACQUITY UPLC ${ }^{\circledR}$ BEH C18 columns (Waters Cop., Milford, Massachusetts, USA)(column specifications: particle size of $1.7 \mu \mathrm{m}, \mathrm{id} .2 .1 \mathrm{~mm} x$ $150 \mathrm{~mm}$ length). The oil samples were solubilised in acetone to form a 5\% w/v solution. Approximately $1 \mu \mathrm{l}$ of the solution was injected through the column maintained at $30^{\circ} \mathrm{C}$. The mobile phase consisted of a mixture of acetone (TEDIA Company, Inc., Fairfield, Ohio, USA) and acetonitrile (Merck KGaA, Darmstadt, Germany) in a volume to volume ratio of 63.5:36.5 and at a fixed flow rate of $0.25 \mathrm{ml} \mathrm{min}^{-1}$. TAG peaks were identified based on the retention times of TAG standards and from earlier published literatures (Ghazali et al., 1995; Sulaiman et al., 1997; Haryati et al., 1998). Individual TAG was quantified by normalisation of the total peak area. The analyses were carried out in duplicate measurements.

\section{Fatty Acid Composition of Raw Materials}

Preparations of fatty acid methyl ester (FAME) for the liquid oil and the gelators were conducted using boron trifluoride method according to $\mathrm{MPOB}$ Test Methods p3.4-Part 1 (2005).

FAME was investigated by using 430-GC gas chromatography (Bruker, Germany). Approximately $1 \mu \mathrm{l}$ of the sample was injected into SGE BPX70 column with dimension of $60 \mathrm{~m} \times 0.25 \mathrm{~mm} \times 0.25$ $\mu \mathrm{m}$ (i.d.). The instrument was fitted with a flame ionisation detector (FID). The carrier gas used were hydrogen and air at a ratio of 1:100. Flow rate of the carrier gas was fixed at $0.8 \mathrm{ml} \mathrm{min}{ }^{-1}$. Detector and injector temperature were set at $200^{\circ} \mathrm{C}$ and $140^{\circ} \mathrm{C}$, respectively. The separation of FAME was performed under isothermal condition at $185^{\circ} \mathrm{C}$. Standard material used for identification of fatty acid was FAME mix RM6 purchased from Supelco (Bellefonte, USA).

\section{Screening of Suitable Gelators and their Dosages}

Screening of suitable gelators and their suitable dosages required for the formation of stable oleogels was conducted. The appropriate amount of gelator was added into $20 \mathrm{ml}$ glass bottles filled with $10.0 \mathrm{~g}$ of superolein and SBO. Blends of superolein and SBO with ratios of 1:4, 1:1, 4:1 and 0:1 were also studied. The mixture was then heated in a $90^{\circ} \mathrm{C}$ water bath shaker to completely dissolve the gelator materials. The resulting homogeneous solutions were cooled to room temperature until the appearance of crystals was confirmed under quiescent conditions. The samples were transferred into incubators at temperatures of $15^{\circ} \mathrm{C}, 20^{\circ} \mathrm{C}$, and $25^{\circ} \mathrm{C}$, to study the stability of the oleogels at temperatures above the slip melting point of the superolein $\left(14.2^{\circ} \mathrm{C}\right)$ and at ambient temperatures $\left(25^{\circ} \mathrm{C}\right)$. Six gelators were 
tested at five dosages as stated in Table 1. Lower dosages were used for formation of SFW oleogels as indicated by Blake et al. (2014). For PBAE oleogels, the dosage selected was based on recommendation of the material supplier. The physical appearance of these oleogels was observed from Day 1 until Day 90 to study the stability of each oleogel via inverted vial approach. When the gel is stable, the substance will not flow when the vial is inverted.

TABLE 1. DOSAGES OF GELATOR USED FOR PRELIMINARY STUDY

\begin{tabular}{lll}
\hline Gelator & Abbreviation & $\begin{array}{c}\text { Dosages, } \\
\%(\mathbf{w} / \mathbf{w})\end{array}$ \\
\hline $\begin{array}{l}\text { Polyglycerol behenic acid ester } \\
\text { Sunflower wax }\end{array}$ & PBAE & $1.0-5.0$ \\
$\begin{array}{l}\text { Fully hydrogenated } \\
\text { monoacylglycerol with }\end{array}$ & SFW & $1.0-5.0$ \\
high palmitic & MGHP & $2.0-10.0$ \\
$\begin{array}{l}\text { Fully hydrogenated } \\
\text { monoacylglycerol with } \\
\text { high stearic }\end{array}$ & MGHO & $2.0-10.0$ \\
$\begin{array}{l}\text { Fully hydrogenated palm } \\
\text { stearin IV 2 }\end{array}$ & & \\
$\begin{array}{l}\text { Hard stearin iodine value (IV) } 14 \\
\text { M }\end{array}$ & PS IV2 & $2.0-10.0$ \\
\hline
\end{tabular}

PSIV2 and PSIV14, respectively. These dosages are still considered very much higher than the other gelators. This indicates that both PSIV2 and PSIV14 are not efficient gelators to form superolein oleogels.

According to Marangoni and Edmund (2012), efficient gelators should have a balance solubility and insolubility in the solvent/liquid oil in order to achieve a proper interaction between the gelator-gelator and gelator-solvent. Doan et al. (2015) reported that higher concentrations of carnauba wild wax $[2 \%(\mathrm{w} / \mathrm{w})]$ and carnauba Brazilian wax $[4 \%(\mathrm{w} / \mathrm{w})]$ were required for gel formation due to their higher solubility in rice bran oil. In this study, the major TAG species of the superolein liquid oil are 1-palmitoyl- 2,3-dioleoyl-glycerol acid (POO) and 1, 3-dipalmitoyl-oleoyl-glycerol (POP) (Table 2), which are made up of mainly C16:0 and C18:1. Similarly, MGHP, MGHO, PSIV2 and PSIV4 have fatty acids with carbon chain length of mainly C16 and C18 (Table 3). This similarity has resulted in high solubility of these gelators in the liquid oil.

In comparison, higher amounts of PSIV2 and PSIV14 were required for the organogelation than MGHO and MGHP because of their higher solubility in the superolein. This is mainly due to PSIV2 and PSIV14 that contained mainly TAG

TABLE 2. FATTY ACID COMPOSITION OF PALM SUPEROLEIN AND GELATORS

\begin{tabular}{|c|c|c|c|c|c|c|c|c|c|c|c|c|}
\hline \multirow[t]{2}{*}{ Sample } & \multicolumn{12}{|c|}{ Fatty acid composition (area \%) } \\
\hline & 12:0 & 14:0 & $16: 0$ & $16: 1$ & 18:0 & 18:1 & 18:2 & $18: 3$ & 20:0 & $20: 1$ & 22:0 & $24: 0$ \\
\hline POoIV64 & 0.4 & 0.9 & 36.7 & 0.3 & 3.5 & 45.2 & 12.4 & 0.3 & 0.2 & - & - & - \\
\hline PBAE & 0.7 & 0.1 & 1.6 & - & 32.6 & 22.8 & 3.5 & - & 9.8 & 0.1 & 26.8 & 1.8 \\
\hline MGHP & 0.5 & 1.2 & 55.1 & - & 41.8 & 0.6 & 0.1 & - & 0.5 & - & - & - \\
\hline MGHO & 0.2 & 0.9 & 40.9 & - & 56.8 & 0.2 & 0.2 & - & 0.6 & - & 0.1 & - \\
\hline PSIV2 & 0.4 & 1.3 & 59.0 & - & 36.1 & 2.5 & 0.1 & - & 0.4 & - & - & - \\
\hline PSIV14 & 0.1 & 1.1 & 81.7 & - & 4.5 & 9.9 & 2.2 & - & 0.3 & - & - & - \\
\hline
\end{tabular}

Note: POoIV64 - palm superolein IV 64; PSIV2 - fully hydrogenated palm stearin IV2; PSIV14 - hard stearin IV14; MGHP - fully hydrogenated monoacylglycerol with high palmitic; MGHO - fully hydrogenated monoacylglycerol with high stearic; PBA - polyglycerol behenic acid ester.

\section{RESULTS AND DISCUSSION}

Figures $1 a$ and $1 b$ show that MGHP and MGHO were having similar patterns of stability due to their very similar composition which contained mainly saturated monoacylglycerol derived from fully hydrogenation of monoacylglycerol from palm stearin and palm olein, respectively (Table 2). It was found that at least $8 \%(\mathrm{w} / \mathrm{w})$ of MGHP and MGHO were needed to form stable oleogels at all the storage temperatures. For PSIV2 and PSIV14, more than $10 \%(\mathrm{w} / \mathrm{w})$ was required to form superolein oleogels that remained stable for 90 days of storage at $20^{\circ} \mathrm{C}$ and $25^{\circ} \mathrm{C}$, as $10 \%(\mathrm{w} / \mathrm{w})$ was still insufficient to form stable gels. At $15^{\circ} \mathrm{C}$, the minimum dosages required were $8 \%(\mathrm{w} / \mathrm{w})$ and $10 \%(\mathrm{w} / \mathrm{w})$ for
TABLE 3. ACYLGLYCEROL COMPOSITION (\%) OF PALM SUPEROLEIN IV 64 (POoIV64)

\begin{tabular}{cc}
\hline Acyglcyerol & Palm superolein $\mathbf{( \% )}$ \\
\hline OLL & $0.60 \pm 0.01$ \\
PLL & $2.66 \pm 0.04$ \\
MLP & $0.51 \pm 0.04$ \\
OLO & $2.08 \pm 0.02$ \\
PLO & $11.47 \pm 0.04$ \\
PLP & $10.51 \pm 0.05$ \\
OOO & $5.71 \pm 0.06$ \\
POO & $32.76 \pm 0.05$ \\
POP & $17.11 \pm 0.18$ \\
SOO & $3.42 \pm 0.06$ \\
POS & $2.44 \pm 0.04$ \\
SOS & $0.28 \pm 0.03$ \\
\hline
\end{tabular}

Note: $\mathrm{O}$ - oleic acid, L - linoleic acid, M - myristic acid, P - palmitic acid, $S$ - stearic acid, IV - iodine value. 

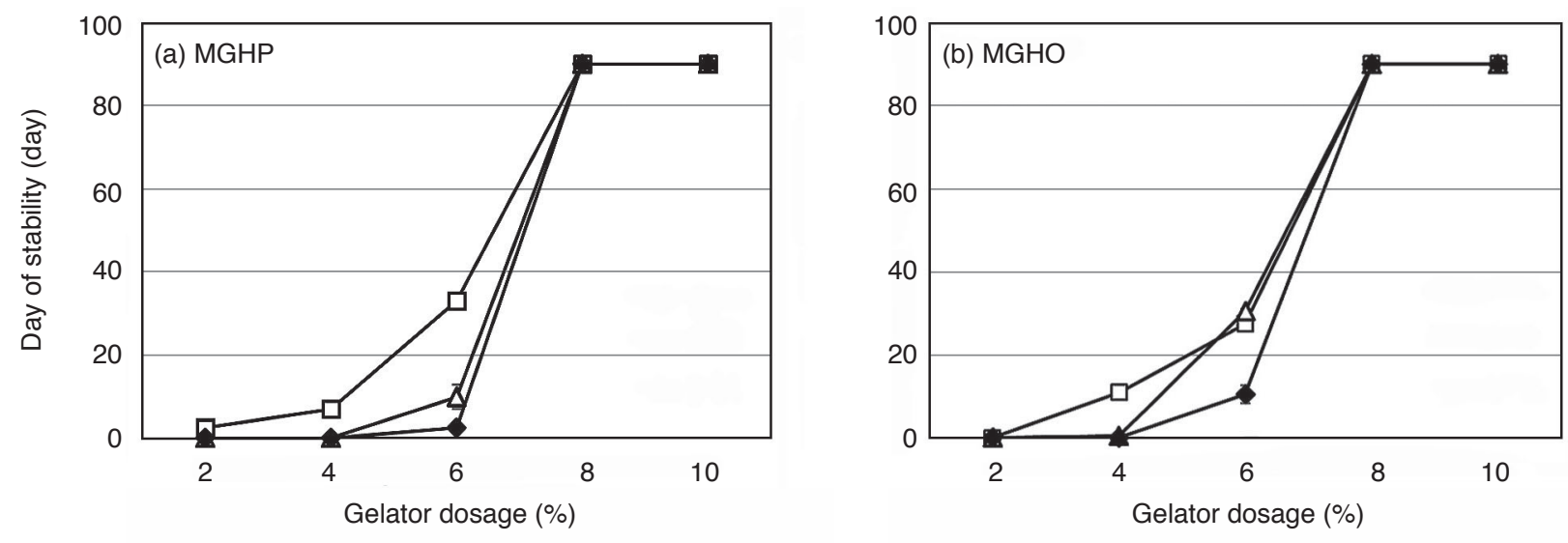

$\neg-15 \% \rightarrow-20 \% \multimap 25 \%$
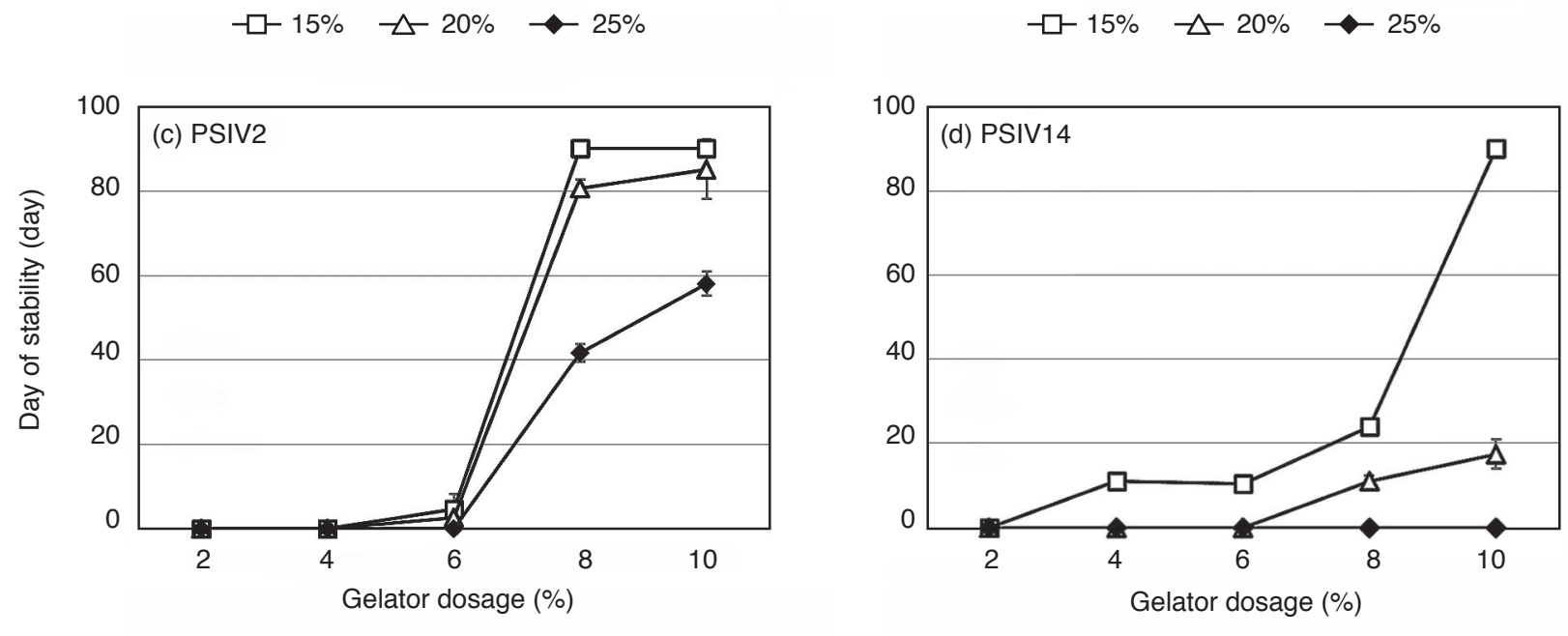

$\neg-15 \% \multimap-20 \% \multimap 25 \%$

$\neg-15 \% \rightarrow-20 \% \quad \neg-25 \%$

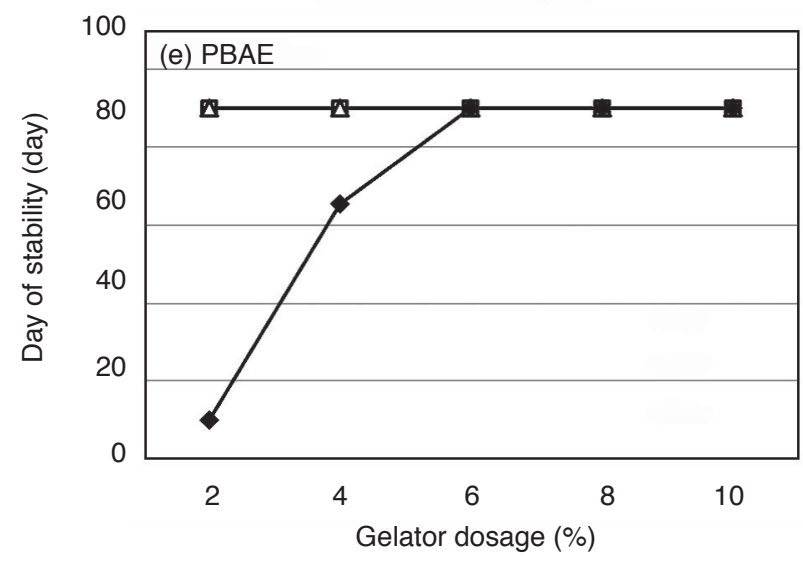

$\neg-15 \% \rightarrow-20 \% \multimap-25 \%$

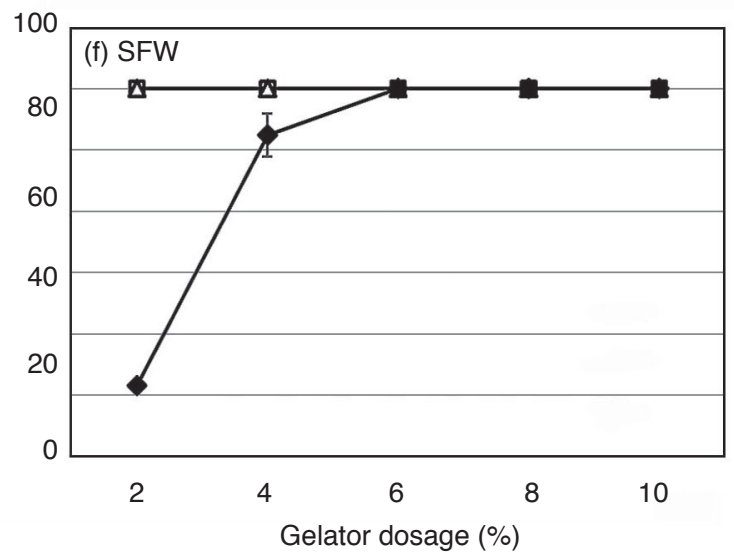

$\neg-15 \% \multimap-20 \% \multimap-25 \%$

Figure 1. Day of stability of superolein oleogels prepared from (a) monoacylglycerol with high palmitic acid (MGHP), (b) monoacylglycerol with high stearic (MGHO), (c) fully hydrogenated palm stearin with IV 2 (PSIV2), (d) hard stearin with IV 14 (PSIV14), (e) polyglycerol behenic acid ester $(P B A E)$, and (f) sunflower wax $(S F W)$ gelators at $15^{\circ} \mathrm{C}, 20^{\circ} \mathrm{C}$ and $25^{\circ} \mathrm{C}$.

possessing similar size and molecular structures as the superolein. These gelators might have higher efficiency when liquid oil used is completely free from saturated fatty acids such as C16:0 and C18:0. In other words, saturated fatty acid in liquid oil may affect the efficiency of gelator molecules in forming strong gel structure and thus reduce the stability of the oleogels formed. Gelators like monoacylglycerol (MAG) and TAG fall under 'crystalline particles' type of organogelators, whereby the structuring is achieved through the formation of colloidal crystalline particles that entraps liquid oil in its structures, causing the formation of gel (Marangoni and Garti, 2011). Although the crystals formation can 
be clearly observed in Figure $2 b$, the concentration of gelator used being too low, the crystalline phase was insufficient to form a network that could trap the liquid oil in the gel-like structure.

Nevertheless, PBAE and SFW were found to be excellent gelators, at which as low as $1 \%(\mathrm{w} / \mathrm{w})$ were sufficient to form superolein oleogels which stabilised for 90 days without any phase separations. PBAE gels formed gel via self-assembly of the PBAE molecules in the superolein oil. As for SFW, the gelation mechanism is different from those using PBAE. SFW contains chemical compounds such as wax esters with fatty alcohols, hydrocarbons, alcohols, phenolic esters, etc. (Carelli et al., 2002). The gel is structured by the arrangement of wax esters into small microcrystalline platelets, which form a complex three-dimensional network upon aggregation of the microcrystalline platelets (Blake et al., 2014).

The physical appearance of the superolein oleogels was shown in Figure 2. It was observed that $8 \%(\mathrm{w} / \mathrm{w})$ of PSIV2 was able to form oleogel without phase separation after one day of preparation. However, the appearance was not transparent as those prepared using PBAE gelator (Figure 1c). Similarly, the oleogels derived from PSIV14 also were not transparent. The phase separation of the oleogel was observed on Day 1 of preparation (Figure 1b). This indicates that $2 \%(\mathrm{w} / \mathrm{w})$ of PSIV14 was unable to form gel structures to hold the liquid oil. Figure 1c illustrates the differences in the appearance particularly the colour and transparency when $1 \%(\mathrm{w} / \mathrm{w})$ of PBAE was used to prepare oleogels with superolein, SBO and blends of $\mathrm{SBO}$ and superolein. The transparency remained unchanged for all the gels but the yellowish colour intensity increased with increasing proportion of the superolein used. This was due to the increase in the concentration of natural pigments, i.e. the carotene and anthocynanins in the liquid oils when higher amount of superolein was used (Siew, 2011).

\section{CONCLUSION}

In conclusion, PBAE and SFW were excellent gelators to structure superolein oil at all the tested temperatures, as low as $1 \%(\mathrm{w} / \mathrm{w})$ were sufficient to form stable oleogels that lasted for 90 days without phase separations. In contrast, PSIV14 showed the lowest ability to form stable superolein oleogels amongst others, as a minimum dosage of $10 \%$ $(\mathrm{w} / \mathrm{w})$ was needed to form stable gels at $15^{\circ} \mathrm{C}$. PSIV2 performed slightly better than PSIV14 as slightly lower dosage of $8 \%(\mathrm{w} / \mathrm{w})$ dosage was sufficient to form stable gels at $15^{\circ} \mathrm{C}$. Both MGHP and MGHO
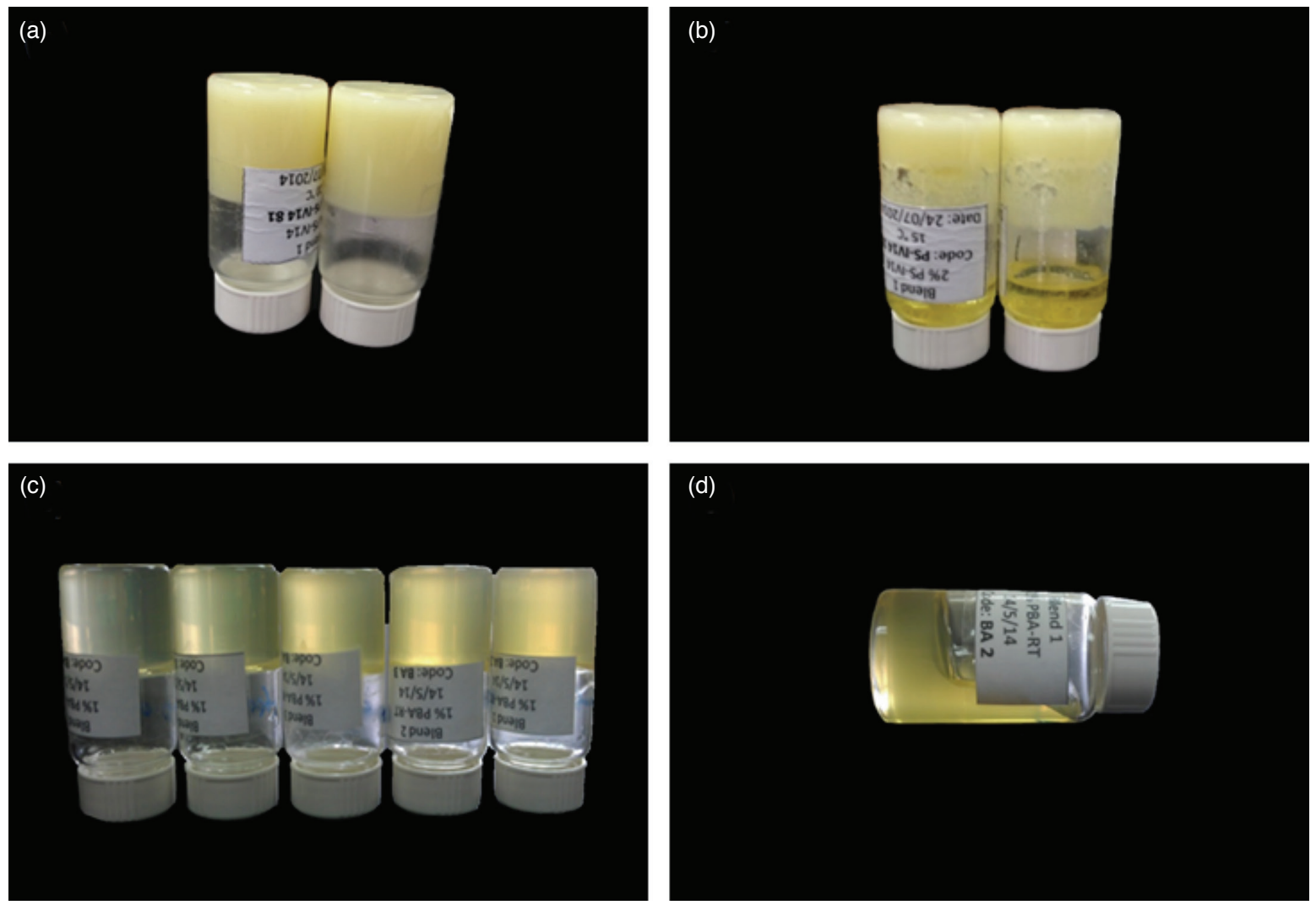

Figure 2. Physical appearance of (a) superolein oleogel with $8 \%$ of fully hydrogenated palm stearin with IV 2 (PSIV2) on Day 1, (b) superolein oleogel with 2\% (w/w) of hard stearin with IV 14 (PSIV14) on Day 1, (c) 1\% (w/w) polyglycerol behenic acid ester (PBAE) oleogels derived from blends of soyabean oil (SBO) and superolein oleogels with ratio of 1:0, 4:1, 1:1, 1:4 and 0:1, and (d) superolein oleogel with 1\% (w/w) PBAE on Day 9. 
performed better than PSIV2 and PSIV14 to form oleogels because lower dosage of the gelators [ $8 \%$ $(\mathrm{w} / \mathrm{w})]$ was able to form oleogels that stabilised at all tested temperatures $\left(15^{\circ} \mathrm{C}, 20^{\circ} \mathrm{C}\right.$ and $\left.25^{\circ} \mathrm{C}\right)$. The purpose of structuring fat using gelator was to reduce the use of high saturated fatty acids component in fat products. Nevertheless, a high dosage of PSIV2 and PSIV14 would significantly increase the total saturation of the end product, thus, the way of structuring might be more similar to the traditional techniques. Therefore, PSIV2 and PSIV14 were screened out for this study as these gelators were inefficient in gelling superolein.

\section{ACKNOWLEDGEMENT}

The authors would like to thank the DirectorGeneral of MPOB for permission to publish this article. The authors thank Ecolex Sdn Bhd for providing the MGHP, MGHO, PSIV2 and PSIV14 gelators. The authors would also like to thank Kuriyama Juhei from Sakamoto Yakuhin Kogyo Co. Ltd for providing the polyglycerol esters additive.

\section{REFERENCES}

AOCS Official Method Ce 5C-89 (2017). Triglycerides in vegetable oils by HPLC. AOCS Official Methods and Recommended Practises of the AOCS. $7^{\text {th }}$ Edition. The American Oil Chemists' Society, Urbana, USA. 4 pp.

AOCS Official Method Ce 5C-93 (2017). Individual triglycerides in oils and fats by HPLC. AOCS Official Methods and Recommended Practises of the AOCS. $7^{\text {th }}$ Edition. The American Oil Chemists' Society, Urbana, USA. 4 pp.

Baran, N; Singh, V K; Pal, K; Anis, A; Pradhan, D K and Pramanik, K (2014). Development and characterization of soy lecithin and palm oilbased organogels. Polymer-Plastics Technology and Engineering, 53: 865-879.

Bin Sintang, M D; Danthine, S; Brown, A; Van De Walle, D; Patel, A R; Tavernier, I; Rimaux, T and Dewettinck, K (2017). Phytosterols-induced viscoelasticity of oleogels prepared by using monoglycerides. Food Research International, 100: 832-840.

Birker, P J M W L and Padley, F B (1987). Physical properties of fats and oils. Recent Advances in Chemistry and Techonology of Fats and Oils (Hamilton, R J and Bhati, A eds.). Elsevier, New York, USA. p. 1-11.
Blake, A I; Co, E D and Marangoni, A G (2014). Structure and physical properties of plant wax crystal networks and their relationship to oil binding capacity. J. Amer. Oil Chem. Soc., 91: 885-903.

Blake, A I and Marangoni, A G (2015). Plant wax crystals display platelet-like morphology. Food Structure, 3: 30-34.

Carelli, A A; Frizzera, L M; Forbito, P R and Crapiste, G H (2002). Wax composition of sunflower seed oils. J. Amer. Oil Chem. Soc., 79: 763-768.

Da Pieve, S; Calligaris, S; Co, E; Nicoli, M C and Marangoni, A G (2010). Shear nanostructuring of monoglyceride organogels. Food Biophysics, 5: 211-217.

Doan, CD; Van De Walle, D; Dewettinck, K and Patel, A R (2015). Evaluating the oil-gelling properties of natural waxes in rice bran oil: Rheological, thermal, and microstructural study. J. Amer. Oil Chem. Soc., 92: 801-811.

Ghazali, H M; Hamidah, S and Che Man, Y B (1995). Enzymatic transesterification of palm olein with nonspecific and 1,3-specific lipases. J. Amer. Oil Chem. Soc., 72: 633-639.

Haryati, T; Che Man, Y B; Ghazali, H M; Asbi, B A and Buana, L (1998). Determination of iodine value of palm oil based on triglyceride composition. J. Amer. Oil Chem. Soc., 75: 789-792.

Hwang, H-S; Kim, S; Singh, M; Winkler-Moser, J K and Liu, S X (2011). Organogel formation of soyabean oil with waxes. J. Amer. Oil Chem. Soc., 89: 639-647.

Hwang, H-S; Kim, S; Evans, K O; Koga, C and Lee, Y (2015). Morphology and networks of sunflower wax crystals in soybean oil organogel. Food Structure, 5: 10-20.

Jang, A; Bae, W; Hwang, H-S; Lee, H G and Lee, S (2015). Evaluation of canola oil oleogels with candelilla wax as an alternative to shortening in baked goods. Food Chemistry, 187: 525-529.

Jin, J; Jie, L; Zheng, L; Cheng, M; Xie, D; Jin, Q and Wang, X (2018). Characteristics of palm midfractions produced from different fractionation paths and their potential usages. International J. Food Properties, 21: 58-69.

Kushairi, A; Loh, S K; Azman, I; Elina, H; Meilina O-A; Zanal Bidin, M N I; Razmah, G; Shamala, S and Ghulam, K A P (2018). Oil palm economic performance in Malaysia and R\&D progress in 2017. J. Oil Palm Res. Vol. 30(2): 163-195. 
Marangoni, A G and Edmund Daniel, C (2012). Organogels: An alternative edible oil-structuring method. J. Amer. Oil Chem. Soc., 89: 749-780.

Marangoni, A G and Garti, N (2011). An overview of the past, present, and future of organogels. Edible Oleogels: Structure and Health Implications (Marangoni, A G and Garti, N eds.). AOCS Press, Urbana. p. 1-17.

Miskandar, M S; Che Man, Y B; Abdul Rahman, R; Nor Aini, I and Yusoff, M S A (2004). Palm oil crystallization: Effect of cooling time and oil content. J. Food Lipids, 11: 190-207.

Miskandar, M S and Nor Aini, I (2010). Palm stearin as low trans hard stock for margarine. Sains Malaysiana, 39: 821-827.

MPOB (2005). Methods of test for palm oil and palm oil products: Preparation of methyl esters of fatty acids-part 4: Rapid method. MPOB Test Methods. MPOB, Bangi. p. 308-309.

Nor Aini, I and Miskandar, M S (2007). Utilization of palm oil and palm products in shortenings and margarines. European J. Lipid Science and Technology, 109: 422-432.

Nur Haqim, I; Miskandar, M S and Rafidah, A H (2018). Influence of palm-based fluid shortening on the physical and textural properties of biscuits. J. Oil Palm Res. Vol. 30(2): 299-305.

Ögutcu, M and Yilmaz, E (2014). Oleogels of virgin olive oil with carnauba wax and monoglyceride as spreadable products. Grasas y Aceites, 63: e040.
Patel, A R; Babaahmadi, M; Lesaffer, A and Dewettinck, K (2015). Rheological profiling of organogels prepared at critical gelling concentrations of natural waxes in a triacylglycerol solvent. $J$. Agricultural and Food Chemistry, 63: 4862-4869.

Pradhan, S; Sagiri, S S; Singh, V K; Pal, K; Ray, S S and Pradhan, D K (2014). Palm oil-based organogels and microemulsions for delivery of antimicrobial drugs. J. Applied Polymer Science, 131: 39979.

Siew, W L (2011). Palm oil. Vegetable Oils in Food Technology Composition, Properties and Uses (Gunstone, F D ed.). Second edition. Wiley-Blackwell, West Sussex. p. 25-58.

Sulaiman, M Z; Sulaiman, N M and Kanagaratnam, $S$ (1997). Triacylglycerols responsible for the onset of nucleation during clouding of palm olein. J. Amer. Oil Chem. Soc., 74: 1553-1558.

Tavernier, I; Doan, C D; Van De Walle, D; Danthine, S; Rimaux, T and Dewettinck, K (2017). Sequential crystallization of high and low melting waxes to improve oil structuring in wax-based oleogels. RSC Advances, 7: 12113-12125.

Toro-Vazquez, J F; Morales-Rueda, J A; DibildoxAlvarado, E; Charó-Alonso, M; Alonzo-Macias, M and González-Chávez, M M (2007). Thermal and textural properties of organogels developed by candelilla wax in safflower oil. J. Amer. Oil Chem. Soc., 84: 989-1000.

Zetzl, A K and Marangoni, A G (2011). Novel strategies for nanostructuring liquid oils into functional fats. Edible Oleogels: Structure and Health Implications (Marangoni, A G and Garti, N eds.). AOCS Press, Urbana. p. 19-47. 